\title{
Posterior fossa decompression with tonsillectomy in 104 cases of basilar impression, Chiari malformation and/or syringomyelia
}

\author{
José Alberto Gonçalves da Silva', Adailton Arcanjo dos Santos Jr. ${ }^{2}$, \\ Luiz Ricardo Santiago Melo', Antônio Fernandes de Araújo', \\ Giseuda Pessoa Regueira ${ }^{3}$
}

\begin{abstract}
The prime objective in the surgical treatment of basilar impression (BI), Chiari malformation $(\mathrm{CM})$ and/or syringomyelia (SM) is based on the restoration of the normal cerebrospinal fluid (CSF) dynamics at the craniovertebral junction through the creation of a large artificial cisterna magna. A small suboccipital craniectomy has been emphasized to avoid caudal migration of the hindbrain structures into the vertebral canal. Nevertheless, the results showed downward migration of the hindbrain related to that type of craniectomy. The authors present, otherwise, the results of 104 cases of $\mathrm{BI}, \mathrm{CM}$ and/or SM, whose surgical treatment was characterized by a large craniectomy with the patient in the sitting position, tonsillectomy, large opening of the fourth ventricle and duraplasty with creation of a large artificial cisterna magna. A significant upward migration of the posterior fossa structures was detected by postoperative magnetic resonance imaging.

Key words: basilar impression, Chiari malformation, hindbrain herniation, tonsillectomy, craniovertebral decompression, syringomyelia.
\end{abstract}

Descompressão da fossa posterior com tonsilectomia em 104 casos de impressão basilar, malformação de Chiari e/ou siringomielia

\section{RESUMO}

O principal objetivo no tratamento cirúrgico da impressão basilar, malformação de Chiari e/ou siringomielia fundamenta-se na restauração dinâmica do líquido cefalorraqueano ao nível da transição craniovertebral e criação de ampla cisterna magna. Uma craniectomia suboccipital de pequenas dimensões foi proposta para evitar a migração caudal de estruturas rombencefálicas no canal vertebral. Entretanto, os resultados evidenciaram migração caudal do rombencéfalo. Os autores apresentam, por outro lado, os resultados de 104 casos de malformação de Chiari e/ou siringomielia, nos quais o tratamento cirúrgico se baseou em ampla craniectomia com o paciente em posição sentada, tonsilectomia, abertura ampla do quarto ventrículo e enxerto dural com consequente criação de ampla cisterna magna. Uma significante migração cranial das estruturas da fossa posterior foi detectada pelo emprego pós-operatório da ressonância magnética. Palavras-Chave: impressão basilar, malformação de Chiari, herniação rombencefálica, tonsilectomia, descompressão craniovertebral, siringomielia.

\section{Correspondence}

José Alberto Gonçalves da Silva

Av. Minas Gerais 1150

58030-092 João Pessoa PB - Brasil

E-mail: jags1803@hotmail.com

Received 5 March 2011

Received in final form 20 May 2011 Accepted 27 May 2011
Basilar impression (BI), Chiari malformation (CM) and syringomyelia (SM) are the most frequent neurodysplasia at the craniovertebral junction. BI was orig- inally described by Ackermann ${ }^{1}$ (1790) in Cretins from the Alps. At that time, he described the small size of the posterior fossa, the elevation of the clivus and

${ }^{1}$ Neurosurgical Division of the Hospital Unimed, João Pessoa PB, Brazil; ${ }^{2}$ Neurosurgical Resident; ${ }^{3}$ Neuroanesthesiologist. 
the projection of the border of the foramen magnum into the posterior fossa. In 1857, Virchow ${ }^{2}$ introduced the term platybasia and in $1876^{3}$ the denomination "basilar impression".

Chiari $^{4,5}(1891,1895)$ described four types of cerebellar anomalies. Type I (14 cases) was characterized by downward displacement of the cerebellar tonsils and the medial portions of the inferior cerebellar lobes, which accompanied the medulla into the cervical spinal canal. Type II (seven cases) showed downward displacement of the portions of the cerebellum (1891), and portions of the inferior vermis (1895), pons, medulla and, at least, a part of the lengthened fourth ventricle, which reached the disc C4-C5, into the enlarged cervical spinal canal. In type III (one case), the hydrocephalic cerebellum, pons and medulla were inside a cervical meningocele (hydroencephaloceles cerebellaris cervicalis), through a spina bifida of the first three cervical vertebrae. In type IV (two cases), there was hypoplasia of the cerebellum without herniation of cerebellar structures into the spinal canal.

With respect to SM, Simon ${ }^{6}$ (1875) introduced the term hydromyelia to designate the dilation of the ependymal canal by cerebrospinal fluid (CSF) and kept the term SM related to cavities that developed independently of the central canal of the spinal cord. It has been unanimously agreed - as can be seen in the present-day literature - that both are in different stages of the same pathological process. However, Finlayson ${ }^{7}$ stated that hydromyelia is considered to be a congenital disturbance due to an incomplete regression of the fetal ependymal canal, whereas SM can be congenital or acquired.

The high prevalence of $\mathrm{BI}$ associated with CM in the Northeast of Brazil was reported by many authors ${ }^{8-13}$, although there is no suitable known reason for this fact.
The main objective of this paper is to analyse the surgical results brought about by the use of a large craniectomy and tonsillectomy with the patient in the sitting position in 104 cases of BI, CM and/or SM.

\section{METHOD}

This study is based on a retrospective review of the patiens, 61 men and 43 women with occipitovertebral malformation, 67 (64.4\%) of whom with BI, 102 (98\%) with CM and 51 (49\%) with SM. All patients underwent "osteodural-neural decompression" previously described by Gonçalves da Silva et al. ${ }^{10}$. This study was approved by the Ethics Committee of the Hospital Unimed, João Pessoa, Brazil.

As far as to surgical technique is concerned, the patients underwent a "osteodural-neural decompression" with large inferior occipital craniectomy in the sitting position, laminectomy varying from $\mathrm{C} 1$ to $\mathrm{C} 3$ level depending on the tonsillar herniation, dural opening in $\mathrm{Y}$ format, dissection of arachnoidal adhesions between the cerebellar tonsils, medulla and spinal cord, large opening of the fourth ventricle, intrapial aspiration of the cerebellar tonsils, suture of the residual pial sacs to the lateral dura mater in ascending position and, finally, a dural grafting was performed with the use of bovine pericardium creating, in this way, a large artificial cisterna magna.

\section{RESULTS}

One hundred and four patients with BI, CM and/or SM were presented. The clinical symptoms observed in the preoperative and follow-up examination are showed in Table 1, the clinical signs in Table 2 and the surgical findings in Table 3. In Table 1 and Table 2 were excluded

Table 1. Clinical symptoms observed in 95 cases of $\mathrm{BI}, \mathrm{CM}$ with tonsillectomy and SM.

\begin{tabular}{|c|c|c|c|c|c|c|c|}
\hline Symptoms & Cases/Number & $\mathrm{R}$ & $\%$ & A & $\%$ & $U$ & $\%$ \\
\hline Headache & 42 & 42 & 100 & - & - & - & - \\
\hline Pain in the neck & 64 & 64 & 100 & - & - & - & - \\
\hline Vertigo & 55 & 50 & 90.9 & - & - & 5 & 9.0 \\
\hline Dysphagia & 33 & 31 & 93.9 & - & - & 2 & 6.0 \\
\hline Nasal reflux & 20 & 16 & 80 & - & - & 4 & 20 \\
\hline Rhinolalia & 42 & - & - & - & - & 42 & 1000 \\
\hline Weakness of limbs & 72 & 33 & 45.8 & 29 & 40.2 & 10 & 13.8 \\
\hline Paresthesia of limbs & 52 & 28 & 53.8 & 10 & 19.2 & 14 & 26.9 \\
\hline Gait disturbances & 44 & 18 & 40.9 & 14 & 31.8 & 12 & 27.2 \\
\hline Anhidrosis & 12 & 5 & 41.6 & 1 & 8.3 & 7 & 58.3 \\
\hline Hyperhidrosis & 13 & 5 & 38.4 & 1 & 7.6 & 7 & 53.8 \\
\hline Syringomyelic aches & 18 & 7 & 38.8 & 1 & 5.5 & 10 & 55.5 \\
\hline
\end{tabular}

R: regressed; A: amelioration; U: unchanged; BI: basilar impression; CM: Chiari marformation; SM: syringomyelia. 
Table 2. Clinical signs observed in 95 cases with tonsillectomy.

\begin{tabular}{|c|c|c|c|c|c|c|c|}
\hline Signs & Cases/Number & $\mathrm{R}$ & $\%$ & A & $\%$ & $\mathrm{U}$ & $\%$ \\
\hline Lesion of the $\mathrm{V}^{\text {th }}$ nerve & 27 & 24 & 88.8 & - & - & 3 & 11.1 \\
\hline Nystagmus & 42 & 15 & 35.7 & - & - & 27 & 64.2 \\
\hline Abolition of gag and palatal reflexes & 54 & 8 & 14.8 & 1 & 1.8 & 46 & 85.1 \\
\hline Lesion of the $\mathrm{XI}^{\text {th }}$ nerve & 51 & 18 & 35.2 & - & - & 33 & 64.7 \\
\hline Lesion of the $\mathrm{XI}^{\text {th }}$ nerve & 3 & 2 & 66.6 & 1 & 33.3 & - & - \\
\hline Hypotony of superior limbs & 50 & 8 & 16.0 & - & - & 42 & 84.0 \\
\hline Spasticity & 49 & 35 & 71.4 & 7 & 14.2 & 7 & 14.2 \\
\hline Paresis of limbs & 69 & 31 & 44.9 & 25 & 36.2 & 13 & 18.8 \\
\hline Hyperreflexia & 73 & 8 & 10.9 & - & - & 65 & 89.0 \\
\hline Hoffmann's sign & 30 & 20 & 66.6 & - & - & 10 & 33.3 \\
\hline Babinski's sign & 28 & 14 & 50.0 & - & - & 14 & 50.0 \\
\hline Rossolimo's sign & 22 & 10 & 45.4 & - & - & 12 & 54.5 \\
\hline Unsteady gait & 44 & 18 & 40.9 & 14 & 31.8 & 12 & 27.2 \\
\hline Hypopallesthesia & 72 & 3 & 4.1 & 1 & 1.3 & 68 & 94.4 \\
\hline Syringomyelic dissociation & 43 & 12 & 27.9 & 13 & 30.2 & 18 & 41.8 \\
\hline Fasciculation & 4 & 1 & 25.0 & 1 & 25.0 & 2 & 50.0 \\
\hline Atrophy & 40 & 9 & 22.5 & 4 & 10.0 & 27 & 67.5 \\
\hline
\end{tabular}

R: regressed; A: amelioration; U: unchanged; BI: basilar impression; CM: Chiari marformation; SM: syringomyelia.

six patients without follow-up and three patients who died. All the cases were followed with clinical studies and craniovertebral MRI for a mean of three years and a range of two months to 20.5 years. The age at surgery ranged from 18 to 74 years, with a mean of 40.7 years.

Sixty-seven out of 104 cases were associated with BI, 102 cases with herniation of the cerebellar tonsils, 74. with herniation of the brainstem, 51 with SM and 1 with syringobulbia, of which 22 patients presented a communication between the fourth ventricle and the hydromyelic cavity. As to SM and/or CM cases, the authors observed 55 cases of blockage of the foramen of Magendie. It was also observed 17 cases of impacted cisterna magna, ten of which were associated with SM without tonsillar herniation by the MRI in the supine position, but the tonsillar herniation appeared with the patient in the sitting position. In five other cases there was not association with SM, the tonsillar herniation also appeared with the patient in the sitting position in three cases and, finally, in two cases was not detected tonsillar herniation with the patient in the sitting position.

The length of the herniated tonsils varied from the end of $\mathrm{C} 1$ to the end of $\mathrm{C} 3$ level, following the caudal migration by $\mathrm{C} 1$ (18 cases), $\mathrm{C} 1$ and $\mathrm{C} 2$ (23 cases), $\mathrm{C} 1$ and C3 (six cases), C2 (31 cases), C2 and C3 (15 cases), and, finally, C3 (nine cases).

The vascular network anomalies in 69 cases were characterized by the missing of the posterior inferior cerebellar artery (PICA) on both sides in four cases, and missing on the left side in two cases, a left hypoplasic PICA in six cases, a left missing and a right large PICA in four cases, a left large and a right hypoplasic PICA in six cases, a right large and a left hypoplasic in seven cases, a right missing and a left hypoplasic PICA in two cases, and, finally, looping sign on the PICAS in 38 cases.

Table 3. Surgical findings observed in 104 cases of BI, CM and SM.

\begin{tabular}{lcc}
\hline Findings & $\begin{array}{c}\text { Cases/ } \\
\text { Number }\end{array}$ & $\%$ \\
\hline Thinning of the occipital bone & 30 & 28.8 \\
Thickening of the occipital bone & 23 & 22.1 \\
Thickening of dural and & 19 & 18.2 \\
Atlanto-occipital ligament & & \\
Pulseless dura mater & 53 & 50.9 \\
Arachnoiditis & 51 & 49.0 \\
Impacted cisterna magna & 17 & 16.3 \\
Blockade of the forame of Magendie & 55 & 52.8 \\
Herniation of the brainstem & 74 & 71.1 \\
Tonsillar herniation & 102 & 98.0 \\
Impacted cisterna magna & 2 & 1.9 \\
without Tonsillar herniation & & \\
Tonsil cyst & 5 & 4.8 \\
Communication of the fourth & 22 & 21.1 \\
ventricle and the hydromyelic cyst & & \\
Vascular network anomaly & 69 & 66.3 \\
Syringobulbia & 1 & 0.9 \\
Syringomyelia & 51 & 49.0 \\
Basilar impression & 67 & 64.4 \\
Hydrocephalus & 4.8 \\
\hline
\end{tabular}

Bl: basilar impression; CM: Chiari marformation; SM: syringomyelia. 

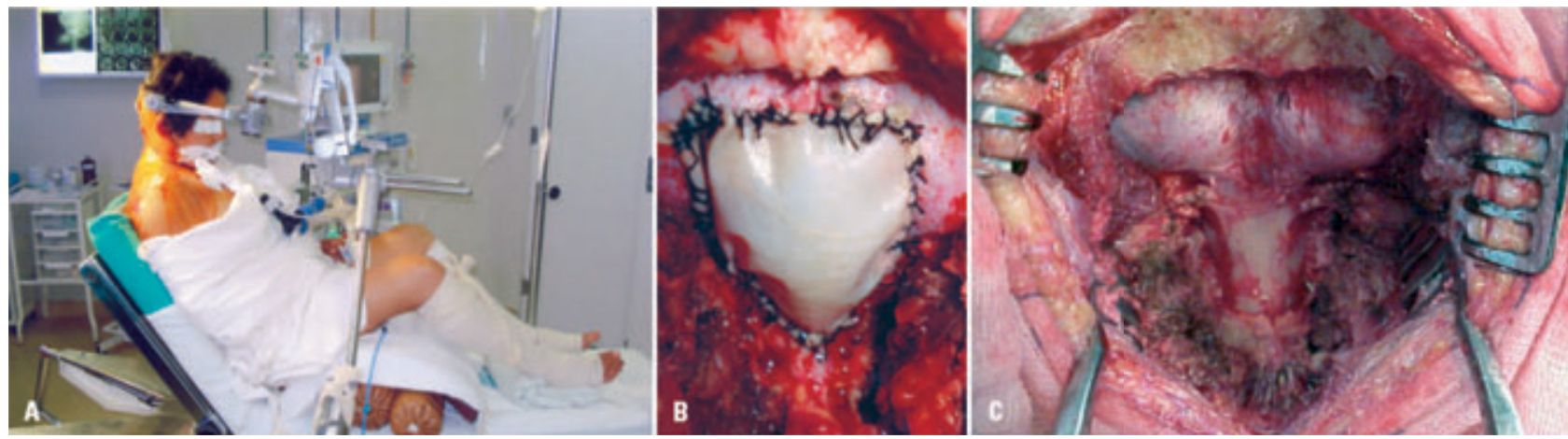

Fig 1. [A] Patient in the sitting position. [B] Duraplasty with creation of an artificial cisterna magna. [C] Large craniectomy of the posterior fossa.
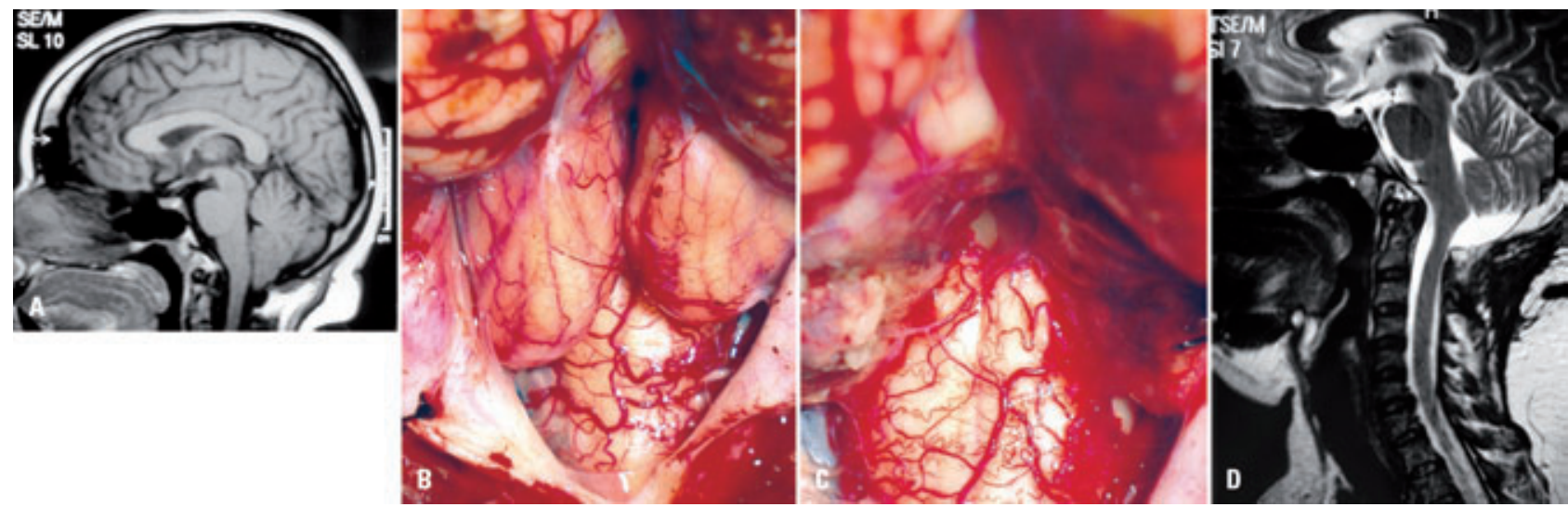

Fig 2. $[A]$ Preoperative MRI demonstrating $C M$ at the level of $C 1$. [B] Extensive herniation of the cerebellar tonsils with the patient in sitting position. [C] Tonsillectomy and large opening of the fourth ventricle. [D] Postoperative MRI showing creation of a large artificial cisterna magna.
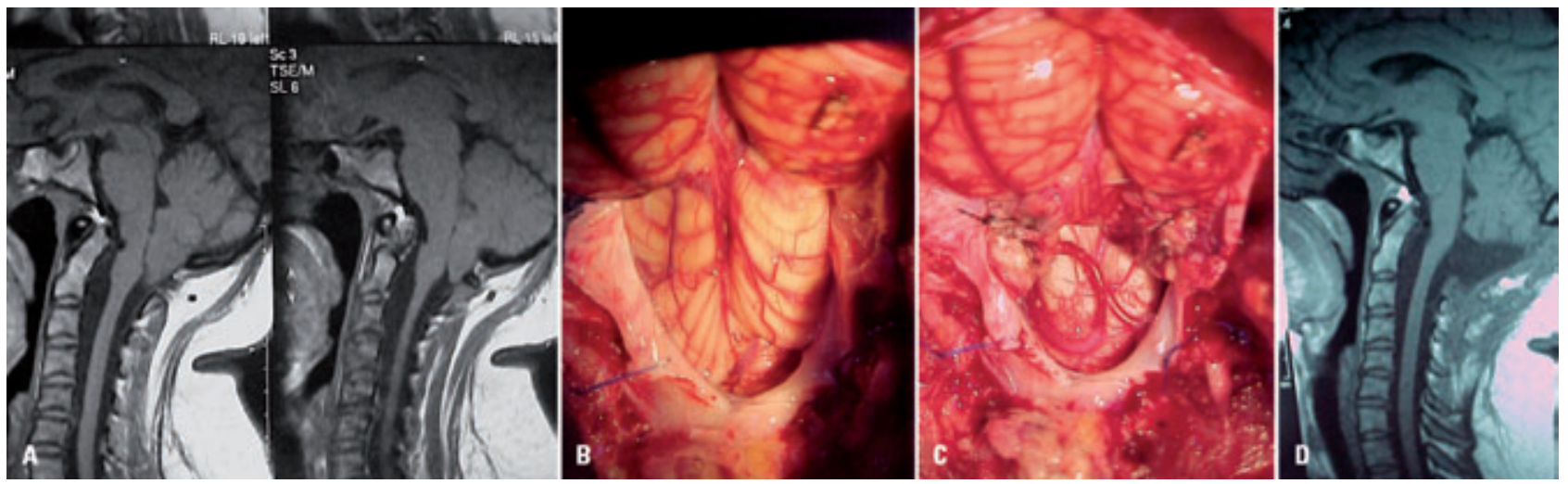

Fig 3. $[A]$ Preoperative MRI depicting basilar impression (BI) and Chiari malformation (CM) at the level C1-C2. [B] More herniation of the cerebellar tonsils in the sitting position at the level of C3. [C] Tonsillectomy, large opening of the fourth ventricle and looping sign on the PICAS. [D] Postoperative MRI showing a large artificial cisterna magna.

\section{DISCUSSION}

The most frequent craniovertebral malformations of clinical importance are characterized by $\mathrm{BI}, \mathrm{CM}$ and SM. BI was originally described by Ackermann ${ }^{1}$ in Cretins from the Alps. He observed a small size of the posterior fossa, an elevation of the clivus, a low topographic situation of transverse sinuses and the projection of the border of the foramen magnum into the posterior fossa, which could not contain one-third of the hindbrain.

Primary BI is a neurodysplasia caused by an abnormal development of the axial neuroskeleton. It frequently comes in association with other congenital anomalies such as atlas assimilation, Klippel-Feil syndrome, Sprengel's deformity, CM, platybasia and SM as reported by 
many authors ${ }^{8-13}$. Its association with others deformities is directly related to the theory of embryogenetic error. In addition, secondary BI is an anomaly of the basioccipital bone related to other abnormalities such as osteomalacia, osteitis deformans, osteogenesis imperfecta and Paget's disease.

The CM, on the other hand, is a caudal rhombencephalon abnormality resulting from the downward migration of the inferior cerebellar portions, mainly the tonsils (CM I) or herniation of the medulla and the caudal portion of the fourth ventricle (CM II), except the pons ${ }^{4,5}$.

With respect to SM, Simon ${ }^{6}$ introduced the term hydromyelia to designate the dilation of the ependymal canal by CSF and kept the term SM to cavities that developed independently of the central canal of the spinal cord. It has been unanimously agreed - as can be seen in the present-day literature - that both are in different stages of the same pathological process. However, hydromyelia is considered to be a congenital disturbance due to an incomplete regression of the fetal ependymal canal, whereas SM can be congenital or acquired ${ }^{7}$.

Many theories have been presented in an attempt to explain the genesis of CM. Experimental studies conducted by Marin-Padilla ${ }^{14}$ revealed that in CM, the basiochondrocranium is smaller due to an underdevelopment of the basioccipital bone. Due to a small posterior fossa, the ulterior development of the cerebellum will cause a herniation of the cerebellar tonsils. According to Marin- Padilla ${ }^{14}$, the development of CM happens as a result of para-axial mesodermal insufficiency after the neural tube closure.

Regarding the surgical technique, all patients of our casuistic of 104 cases were operated in the sitting position which facilitates the surgical procedure. Gardner and Goodall ${ }^{15}$ used this type of position for the operation of 13 out of 17 patients with CM.

The extension of the craniectomy varies in the literature. Because of the small size of the posterior fossa caused by BI and/or CM, especially when both anomalies are present, we prefer to use a large craniectomy which extends cranially to the transverse sinuses - frequently situated lower than those in normal persons - and laterally to $3-4 \mathrm{~cm}$ from the midline. The main reason for this large opening is to increase the volume of the posterior fossa and to create a large artificial cisterna magna, commonly absent in cases of hindbrain herniation, permitting, in this way, an upward migration of the herniated portions of the cerebellum and brainstem.

Batzdorf ${ }^{16}$ and Duddy and Williams ${ }^{17}$ stated that the herniation of the cerebellar structures and brainstem, as observed in the postoperative period, are attributed to a large craniectomy. A small craniectomy, on the contrary, might have prevented a decompression from maintained the blockage of the CSF flow and perpetuating, in this way, the craniospinal pressure dissociation.

Duddy and Williams ${ }^{17}$, however, using a small craniectomy, revealed a frequent downward migration of the cerebellum and brainstem, and pointed this out as a cause of poor results. These authors observed a downward migration of the posterior fossa structures in 53\% of their patients, whereas no change was noticed in $41 \%$ and a cranial migration of the hindbrain was observed in only one case.

Sahuquillo et al..$^{18}$ compared the results obtained in 10 cases in which a small craniectomy was performed, with other 10 patients that underwent an extensive craniectomy. An upward migration of the cerebellum and brainstem was observed in all the last patients, while in those which a small craniectomy was performed there was a downward migration in 7 patients.

The volume of the posterior fossa is notoriously reduced in cases of $\mathrm{BI}$ and/or CM as firstly described by Ackermann ${ }^{1}$. In recent times, however, some authors ${ }^{19,20}$ using X-ray, computed tomography and magnetic resonance imaging (MRI) examinations have also demonstrated that the posterior fossa volume, in the presence of $\mathrm{BI}$ and $\mathrm{CM}$, is smaller than those observed in normal people. Milhorat et al. ${ }^{21}$ verified a decrease of $13.4 \mathrm{~mL}$ in the total volume of the posterior fossa and 40\% (10.8 $\mathrm{mL}$ ) in the CSF volume of this region.

Regarding the cerebellar tonsils, the majority of the neurosurgeons ${ }^{21-26}$ leave them intact, performing especially the opening of the fourth ventricle, as we performed in 192 cases of our casuistic. Other surgeons ${ }^{10,12,23}$, as observed in recent publications, recommend the dissection of the arachnoidal adherences of the tonsils and vessels and opening of the fourth ventricle. Furthermore, they recommend tonsillectomy as a protection against slump, eliminating the compressive effect over the medulla and spinal cord, as described by Williams ${ }^{25}$, as well as it contributes to the creation of a large artificial cisterna magna, which facilitates an upward migration of the hindbrain structures. Williams ${ }^{25}$ also recommended to remove part of the tonsils to ensure that the pathways are maximally opened. On the other side, Batzdorf ${ }^{26}$ recommends lightly diathermying the pia mater over the surface of the tonsils. Williams ${ }^{25}$ admitted that creating an artificial cisterna magna is better effected by a more substantial removal, causing no morbidity after evacuation.

Iskandar et al. ${ }^{27}$ reported on five pediatric cases of SM without hindbrain herniation. All patients improved after undergoing posterior fossa decompression. Kyoshima et al. ${ }^{28}$ described four similar cases with a good recovery of the patients after the decompressive operation. The au- 
thors named the full cisterna magna as "tight cisterna magna" and designated Iskandar's description as "Chiari 0 malformation". Gonçalves da Silva et al. ${ }^{29}$ named this type of cisterna magna as "impacted cisterna magna".

The authors observed the presence of the "impacted cisterna magna" in 17 out of the 104 cases. In ten consecutive patients with SM, no hindbrain herniation was detected by MRI in the supine position, but the herniation of the cerebellar tonsils was observed in all of them during the surgery in the sitting position ${ }^{30}$. In other five patients without SM there was no tonsillar herniation showed by MRI in the supine position, however, in the sitting position, they migrated caudally in three cases and, finally, in the other two patients, the cerebellar tonsils did not herniate.

Not only the cerebellar tonsils but also the brainstem and cerebellum have the tendency to migrate downward in the sitting position. In this way, we observed herniation of the cerebellar tonsils in 102 (98\%) patients and downward migration of the brainstem in 74 (71.1\%).

SM was observed in 51 (49\%) patients, of which there was a communication between the fourth ventricle and the hydromyelic cyst in 22 cases (43.1\%). Syringobulbia was detected in only one patient $(0.9 \%)$. Blockage of the foramen of Magendie was observed in 55 (52.8\%) patients, mainly caused by the presence of a dense membrane or adhesions between the cerebellar tonsils. Gardner and Goodall ${ }^{15}$ described in many cases obstruction of the foramen of Magendie by a membrane representing an unperforated rhombic roof.

The vascular network anomalies in 69 cases were characterized by the missing of the left PICA in two cases, absence of both PICAS in four cases, a missing left PICA and a right large PICA in four cases, a left hypoplasic PICA in six cases, a left large PICA and a right hypoplasic PICA in six cases, a right large PICA and a left hypoplasic PICA in seven cases, a right missing PICA and a left hypoplasic PICA in two cases and, finally, looping sign on the PICAS in 38 cases.

As to postoperative complications, it was observed transient respiratory distress syndrome in two cases that resulted in death in one of them. Four cases of CSF fistula were treated with the use of external ventricular drainage with complete closure of the CSF leakage in two patients and one associated with hydrocephalus underwent a ventriculoperitoneal shunt (VPS). The authors observed pseudomeningocele (PM) in five cases, from these two associated with hydrocephalus underwent VPS, one patient underwent a lumboperitoneal shunt, other patient was reoperated and in just one case of PM, the reoperation was not indicated because of postoperative MRI did not reveal compression signs of the hindbrain structures. We have detected others complications such as hyper- tensive cerebral haemorrhage, epidural hematoma, hiccups in two cases, from these one lasted two days and the other lasted 20 days ceasing the hiccups only with the use of cyclobenzaprine, hypertensive pneumocephalus in two patients associated with hydrocephalus treated with VPS and, finally, two cases of hallucination lasted 24 hours in one patient and three days in another.

The causes of postoperative death in three patients should not happen in two. One patient with respiratory distress by the intubation was used a forced mistaken retroflection of the head, which provoked lesion of the brainstem and the consequent death. An other had a hypertensive cerebral haemorrhage and died, and by the last one was observed a epidural hematoma recurrance, in which failed the intubation and the patient died.

Taking into account, however, the promising clinical outcomes as seen in the present study, we have felt encouraged to justify our choice of "osteodural-neural decompression" associated with tonsillectomy as used in this group of patients.

ACKNOWLEDGEMENTS - This paper is dedicated with thanks to Ricardo Vieira Botelho, MD, PhD, São Paulo.

\section{REFERENCES}

1. Ackermann JF. Über die Kretinen, eine besondere Menschenabart in den Alpen.Gotha, in der Ettingerschen Buchhandlung, 1790.

2. Virchow R. Untersuchungen über die Entwicklung des Schädelgrundes im gesunden krankhaften Zustand und über den Einfluss Derselben auf Schädelform, Gesichtsbildung und Gehirnbau. Berlin, 1857.

3. Virchow R. Beiträge zur physischen Anthropologie der Deutschen mit besonderer Berücksichtigung der Friesen. Buchdruckerei der königlichen Akademie der Wissenschaften, G. Vogt, Berlin, 1876.

4. Chiari H. Über Veränderungen des Kleinhirns infolge von Hydrocephalie des Grosshirns. Dtsch med Wschr 1891;17:1172-1175.

5. Chiari H. Über Veränderungen des Kleinhirns, des Pons und der Medulla Oblongata in Folge von congenitaler Hydrocephalie des Grosshirns. Dtsch Akd Wissensch 1895;63:71-125.

6. Simon Th. Beiträge zur Pathologie und pathologischen Anatomie des Central-Nervensystem. Arch Psychiat Nervenkr 1875;5:108-163.

7. Finlayson AI. Syringomyelia and related conditions. In: Baker AB, Baker LH (Eds). Clinical Neurology, vol 3, Philadelphia, 1981: 1-17.

8. Canelas HM, Zaclis J, Tenuto RA. Contribuição ao estudo das malformações occipito-cervicais, particularmente da impressão basilar. Arq Neuropsiquiatr 1952;10:407-476.

9. Caetano de Barros M, Farias W, Ataíde L, Lins S. Basilar impression and Arnold-Chiari malformation. J Neurol Neurosurg Psychiatry 1968;31: 595-605.

10. Gonçalves da Silva JA, Holanda MMA. Basilar impression, Chiari malformation and syringomyelia. A retrospective study of 53 surgically treated patients. Arq Neuropsiquiatr 2003;61:368-375.

11. Carneiro GS Filho. Tratamento cirúrgico-circunferencial da invaginação basilar. Tese, Recife, 2001.

12. Arruda JAM, Costa CMC, de Tella Jr OI. Results of the treatment of syringomyelia associated with Chiari malformation: analysis of 60 cases. Arq Neuropsiquiatr 2004;62:237-244.

13. Botelho RV, Bittencourt LRA, Rotta JM, Tufik S. The effects of posterior fossa decompressive surgery in adult patients with Chiari malformation and sleep apnea. J Neurosurg 2010;112:800-807.

14. Marin-Padilla M. Cephalic axial skeletal-neural dysraphic disorders: embryology and pathology. Can J Neurol Sci 1991;18:153-169.

15. Gardner WJ, Goodall RJ. The surgical treatment of Arnold-Chiari malformation in adults. An explanation of its mechanism and importance of encephalography in diagnosis. J Neurosurg 1950;3:199-206. 
16. Batzdorf U. Syringomyelia: current concepts in diagnosis and treatment. Williams \& Wilkins, Baltimore, 1991.

17. Duddy MJ, Williams B. Hindbrain migration after decompression for hindbrain hernia: a quantitative assessment using MRI. Brit J Neurosurg 1991; 5:141-152.

18. Sahuquillo J, Rubio E, Poca MA, Rovira A, Rodriguez-Baeza A, Cervera C. Posterior fossa reconstruction: a surgical technique for the treatment of Chiari I malformation and Chiari I/syringomyelia complex-preliminary results and magnetic resonance imaging quantitative assessment of hindbrain migration. Neurosurgery 1994;35:874-885.

19. Nyland H, Krogness KG. Size of posterior fossa in Chiari type I malformation in adults. Acta Neurochirurgica 1978;40:233-242.

20. Heiss JD, Patronas N, DeVroom HL, et al. Elucidating the pathophysiology of syringomyelia. J Neurosurg 1999;91:553-562.

21. Milhorat $\mathrm{TH}, \mathrm{Chou}$ MW, Trinidad EM, et al. Chiari I malformation redefined: clinical and radiographic findings for 364 symptomatic patients. Neurosurgery 1999;44:1005-1017.

22. Romero FR, Pereira CAB. Suboccipital craniectomy with or without duraplasty. What is the best choice in patients with Chiari type I malformation? Arq Neuropsiquiatr 2010;68:623-626.

23. Taricco MA. Tratamento cirúrgico da siringomielia associada à malformação de Chiari tipo I. Tese, São Paulo, 1994.

24. Raftopoulos C, Sanchez A, Matos C, Balériaux D, Bank WO, Brotchi J.
Hydrosyringomyelia-Chiari I complex. Prospective evaluation of a modified foramen magnum decompression procedure: preliminary results. Surg Neurol 1993;39:163-169.

25. Williams B. Surgery for hindbrain related syringomyelia. In Advances and technical standarts in neurosurgery, vol 20, Berlin, Springer Verlag, 1993; 108-164.

26. Batzdorf U. Chiari I malformation with syringomyelia. Evaluation of surgical therapy by magnetic resonance imaging. J Neurosurg 1988;68: 726-730.

27. Iskandar BJ, Hedlund GL, Grabb PA, Oakes WJ. The resolution of syringohydromyelia without hindbrain herniation after posterior fossa decompression. J Neurosurg 1998;89:212-216.

28. Kyoshima K, Kuroyanagi T, Oya F, Kamijo Y, El-Noamany H, Kobayashi S. Syringomyelia without hindbrain herniation: tight cisterna magna. Report of four cases and a review of the literature. J Neurosurg (Spine 2) 2002;96:239-249.

29. Gonçalves da Silva JA, Leiros da Costa MD, Melo LRS, Araújo AF, Almeida EB. Impacted cisterna magna without syringomyelia associated with lancinating headache, throbbed nuchal pain and paraparesis treated by posterior fossa decompression. Arq Neuropsiquiatr 2007;65:1228-1232.

30. Gonçalves da Silva JA, Melo LRS, de Araújo AF, dos Santos Jr. Resolution of syringomyelia in ten cases of "up- and- down Chiari malformation" after posterior fossa decompression. Arq Neuropsiquiatr 2010;68:694-699. 